К. КАЛДЕР, Э. КУРГПЫЛЬД,

В. МИХКЕЛЬСОО, Х. НИЕДРАЙС

\title{
УСТАНОВКА ДЛЯ ИССЛЕДОВАНИЯ КИНЕТИКИ ЗАТУХАНИЯ ЛЮМИНЕСЦЕНЦИИ В ИМПУЛЬСНЫХ МАГНИТНЫХ ПОЛЯХ дО 30 Т
}

\author{
(Представил К. К. Ребане)
}

Сильные импульсные магнитные поля применяются, например, для исследования циклотронного резонанса $\left[{ }^{1}\right]$ и эффекта Фарадея $\left[{ }^{2}\right]$ в полупроводниках или эффекта Зеемана в узкополосных спектрах сложных молекул $\left[{ }^{3}\right]$.

В настоящей статье описывается установка, собранная на базе криостата со встроенным импульсным соленоидом, для исследования кинетики затухания люминесценции в сильных импульсных магнитных полях до 30 Т при температуре $4,2 \mathrm{~K}$. Такие исследования позволяют получить информацию о мультиплетных возбужденных состояниях центров люминесценции в кристаллах (о симметрии центра, величинах расщеплений, вероятностях излучательных переходов), особенно в тех случаях, когда наблюдение зеемановских расщеплений мультиплета невозможно ни по оптическим спектрам, из-за большой ширины полос люминесценции и поглощения, ни методом оптически детектируемого электронного парамагнитного резонанса, из-за большого $\left(>10^{-4}\right.$ эВ) расщепления мультиплета. в нулевом поле.

\section{Криостат с импульсным соленоидом}

Конструкция гелиевого криостата с импульсным соленоидом показана на рис. 1. Исследуемый объект находится в жидком гелии. Излучение вводится и выводится в горизонтальном направлении вдоль силовых линий магнитного поля.

Основные узлы криостата изготовлены из нержавеющей стали. Цилиндрический корпус криостата состоит из двух частей (1) и (2). Сквозь стенку (1) проходят трубка ввода жидкого гелия (3) в гелиевый сосуд и трубка вывода паров гелия (4), через которую вводятся также электрические провода в гелиевый сосуд. Торцы корпуса выполнены в виде съемных фланцев $(5,6)$, имеющих кварцевые окна $(7,8)$ для ввода и вывода излучения.

K корпусу (2) приварена горловина (9), а она, в свою очередь, к цилиндрическому сосуду жидкого азота (10). Один из торцов сосуда выполнен в виде съемного фланца (11), к внутренней стороне которого крепится с помощью кронштейнов (12) соленоид (13).

Соленоид намотан в 7 слоев по 18 витков медным проводом марки ПСД с сечением $1,45 \times 4,1$ м $^{2}$. Витки изолированы друг от друга эпоксидным компаундом, а слои еще и стеклотканью. Внутренний диаметр соленоида 27 мм, внешний 59 мм, длина 80 мм. Соленоид запрессован в цилиндрический стальной бандаж с толщиной стенки 40 мм. В осевом направлении бандаж стягивается с помощью болтов 


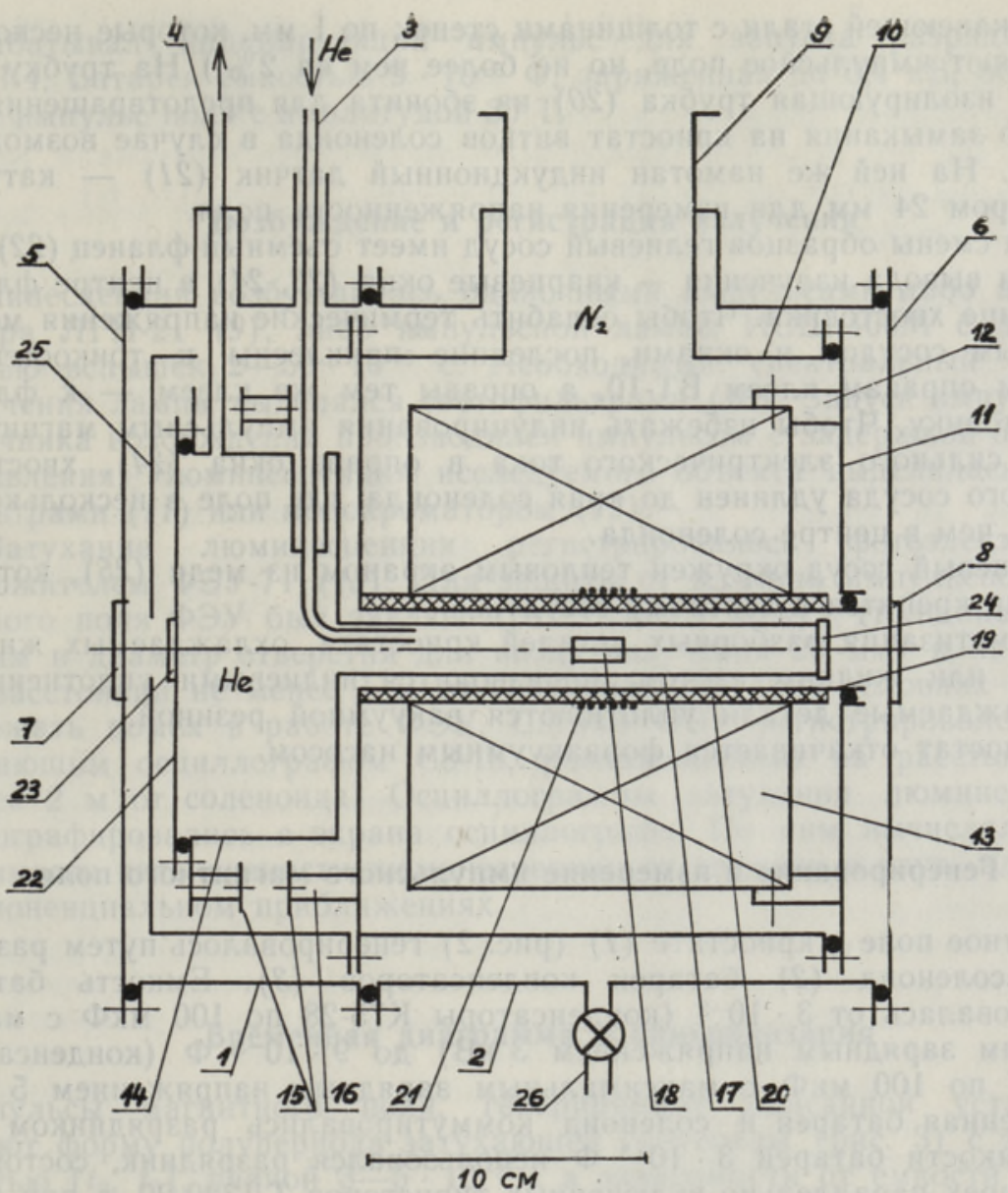

Рис. 1. Азотно-гелиевый криостат с импульсным соленоидом: $1,2-$ части корпуса, 3 - трубка ввода жидкого гелия, 4 - трубка вывода паров гелия, 5,6 - фланцы, 7,8 - кварцевые окна, 9 - горловина для заливки жидкого азота, 10 - сосуд жидкого азота, 11 - фланец, 12 - кронштейны, 13 - соленоид, 14 - сосуд жидкого гелия, 15 кольца, 16 - втулки, 17 - хвостовик гелиевого сосуда, 18 - образец, 19 - трубка, 20 - изолирующая трубка, 21 - индукционный датчик, 22 - фланец, 23,24 - кварцевые окна, 25 - тепловой экран, 26 к насосу.

фланцами толщиной 20 мм. Кабели питания импульсным током подводятся к соленоиду через горловину для заливки жидкого азота.

Перед началом эксплуатации была проведена тренировка соленоида путем генерирования им импульсов поля с постепенно увеличивающимися амплитудами до $40 \mathrm{~T}$.

Гелиевый сосуд (14) скреплен с азотным сосудом (10) двумя кольцами (15) и девятью втулками (16), соединяющими кольца между собой и с сосудами так, чтобы путь теплопроводности оказался в несколько раз длиннее расстояния между сосудами.

Гелиевый сосуд имеет горизонтальный хвостовик (17) диаметром 12 мм, куда помещаются исследуемый образец (18) и датчик температуры - угольный пезистор. Чтобы вставить этот хвостовик в полость соленоида, вдоль оси азотного сосуда имеется полость, образованная трубкой (19) диаметром 20 мм. (Таким образом, между исследуемым объектом и обмоткой соленоида расположены две трубки (17) и (19) 
йз нержавеющей стали с толщинази стенок по 1 мм, которые нескольк̌̄ô ослабляют импульсное поле, но не более чем на 2\%.) На трубку (19) надета изолирующая трубка (20) из эбонита для предотвращения короткого замыкания на криостат витков соленоида в случае возможной аварии. На ней же намотан индукционный датчик (21) - катушка диаметром 24 мм для измерения напряженности поля.

Для смены образцов гелиевый сосуд имеет съемный фланец (22), для ввода и вывода излучения - кварцевые окна $(23,24)$ в центре фланца и в конце хвостовика. Чтобы ослабить термические напряжения между гелиевым сосудом и окнами, последние приклеены к тонкостенным медным оправам клеем ВТ-10, а оправы тем же клеем - к фланцу и хвостовику. Чтобы избежать индуцирования импульсным магнитным полем сильного электрического тока в оправе окна (24), хвостовик гелиевого сосуда удлинен до края соленоида, где поле в несколько раз слабее, чем в центре соленоида.

Гелиевый сосуд окружен тепловым экраном из меди (25), который болтами крепится к азотному сосуду.

Герметизация разборных деталей криостата, охлаждаемых жидким гелием или жидким азотом, производится индиевыми уплотнениями. Неохлаждаемые детали уплотняются вакуумной резиной.

Криостат откачивается форвакуумным насосом.

\section{Генерирование и измерение импульсного магнитного поля}

Магнитное поле в криостате (1) (рис. 2) генерировалось путем разряда через соленоид (2) батареи конденсаторов (3). Емкость батареи варьировалась от $3 \cdot 10^{-3}$ (конденсаторы К75-28 по 100 мкФ с максимальным зарядным напряжением 3 кВ) до $9 \cdot 10^{-3} \Phi$ (конденсаторы КЧ1И7 по 100 мкФ с максимальным зарядным напряжением 5 кВ). Заряженная батарея и соленоид коммутировались разрядником (4). При емкости батареи $3 \cdot 10^{-3}$ Ф использовался разрядник, состоящий из четырех параллельно включенных тиристоров ТД320-20, а при бо́льших емкостях батареи - вакуумный разрядник, в котором ионизация осуществлялась с помощью дополнительных электродов.

Зависимость напряженности магнитного поля $H$ от времени в отдельном импульсе определялась интегрированием эдс, наведенной полем в индукционном датчике (5) криостата. Для этого применялись интегратор импульсного напряжения ИИН-4 * (6) и запоминающий осциллограф С8-13 (7).

Блок управления (8) управлял зарядом батареи конденсаторов от высоковольтного выпрямителя, доводя напряжение до необходимого, и

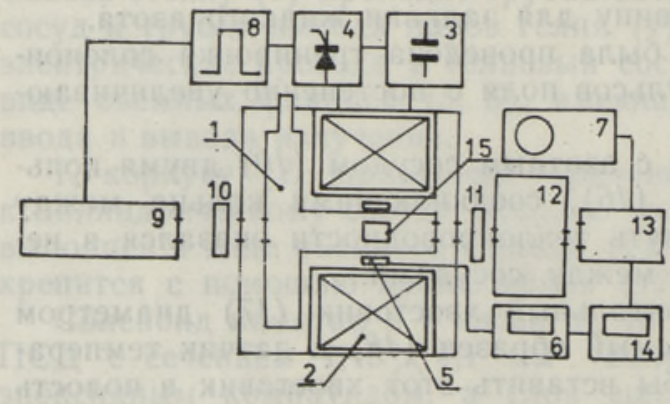

Рис. 2. Блок-схема установки: 1 - криостат, 2 - соленонд, 3 батарея конденсаторов, 4 - разрядник, 5 - индукционный датчик, 6 интегратор импульсного напряжения ИИН-4, 7 - осциллограф С $8-13,8$ блок управления, 9 - импульсный источник возбуждения (лазер ЛГИ-21 или импульсная лампа ИСШ-400М), 10, 11 - светофильтры, 12 - монохроматор, 13 - фотоэлектронный умножитель ФЭУ-71, 14 - частотомер Ч3-34, 15 - образец.

* ИИН-4 разработан в Институте физики совмегтно с Тартуским филиалом СКБ АН ЭСCP. 
вырабатывал инициирующий импульс для запуска ра́зрядника иं ИИН-4. Батарея емкостью $9 \cdot 10^{-3} \Phi$, заряженная до 3,4 кВ, обеспечивала импульс поля с амплитудой $30 \mathrm{~T}$.

\section{Возбуждение и регистрация излучения}

Люминесценция возбуждалась одиночными импульсами либо азотного лазера ЛГИ-21 (9), либо импульсной лампы ИСШ-400М с длительностью вспышек $2-50 \cdot 10^{-6}$ с. Необходимый спектральный участок излучения лампы выделялся светофильтрами (10). Запуск импульсного источника возбуждения производился импульсом с задержкой от блока управления. Люминесценция исследуемого объекта выделялась светофильтрами (11) или монохроматором (12).

Затухание люминесценции регистрировалось фотоэлектронным умножителем ФЭУ-71 (13). Для защиты от влияния импульсного магнитного поля ФЭУ был заключен в стальной кожух (толщина стенок 10 мм и диаметр отверстия для ввода излучения 20 мм) и находился на расстоянии не менее 1 м от соленоида. В таких условиях удалось избежать помех в работе ФЭУ. Сигнал ФЭУ регистрировался запоминающим осциллографом С $8-13$, расположенным на расстоянии не менее 2 м от соленоида. Осциллограммы затухания люминесценции фотографировались с экрана осциллографа. По ним вычислялись зависимости интенсивности люминесценции от времени в двух-или одноэкспоненциальном приближениях.

\section{Временная диаграмма и синхронизация}

Импульсы магнитного поля, генерируемые описанной установкой, имеют форму полупериода затухающей синусоиды (рис. 3) с длительностью $\left[t_{0}, t_{5}\right]$, равной $3-5 \cdot 10^{-3}$ с в зависимости от емкости конденсаторной батареи. В них можно выделить расположенный около максимума интервал времени $\left[t_{1}, t_{4}\right]$, равный $5-8 \cdot 10^{-4} \mathrm{c}$, в течение которого изменение магнитного поля составляет не более $\pm 2 \%$.

Синхронизация в работе приборов обеспечивала попадание интервала $\left[t_{2}, t_{3}\right]$ регистрации затухания люминесценции внутрь интервала квазипостоянства поля $\left[t_{1}, t_{4}\right]$. Благодаря этому удалось провести исследования кинетики люминесценции в условиях почти постоянного магнитного поля, несмотря на импульсный способ его генерирования.

$\mathrm{B}$ момент $t_{0}$ ннициирующим импульсом от блока управления запускались разрядник и ИИН-4, а в момент $t_{2}$ импульсом с задержкойимпульсный источник возбуждения, развертка осциллографа С8-13, регистрирующего затухание люминесценции, и частотомер Ч3-34. Дли-

Рис. 3. Кривая зависимости напряженности магнитного поля от времени: $t_{0}-$ момент запуска разрядника, $t_{1}$ - начало интервала квазипостоянства поля, $t_{2}$ - момент запуска импульсного источника возбуждения и развертки осциллографа, $t_{\mathrm{m}}$ - момент максимальной напряженности магнитного поля, $t_{3}-$ конец развертки осциллографа, $t_{4}-$ конец интервала квазипостоянства поля, $t_{5}-$ конец импульса поля.

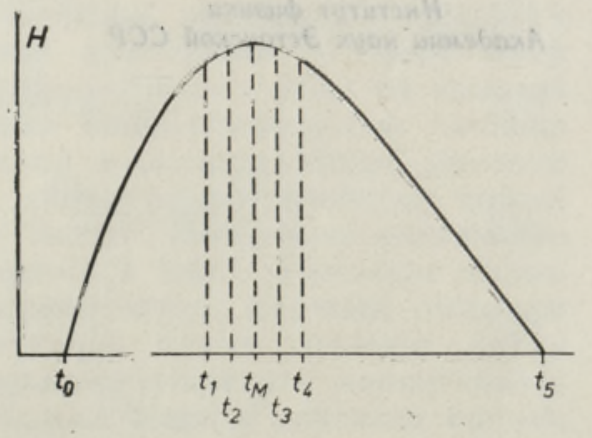


тельность регистрации $\left[t_{2}, t_{3}\right] 5-500 \cdot 10^{-6}$ с определялась разверткой осциллографа. ИИН-4 вырабатывал импульс индикации момента $t_{\text {}}$, соответствующего максимуму поля. Интервал $\left[t_{2}, t_{\mathrm{M}}\right]$ измерялся частотомером. По его величине проверялось нахождение интервала измерения $\left[t_{2}, t_{3}\right]$ внутри интервала квазипостоянства поля $\left[t_{1}, t_{4}\right]$.

\section{Исследование кинетики затухания люминесценции}

На установке проведены исследования кинетики затухания люминесценции $\mathrm{KCl}, \mathrm{KBr}$ и $\mathrm{KI}$, активированных $\mathrm{Sn}^{2+}(H$ до $15 \mathrm{~T}) \quad\left[{ }^{4,5}\right]$, и $\mathrm{KI}$, активированного $\mathrm{In}^{+}$( $H$ до $\left.30 \mathrm{~T}\right)$.

В качестве примера приведем данные о влиянии сильного магнит-

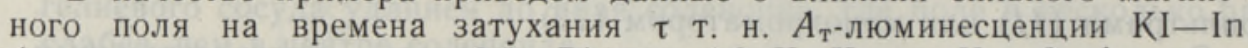
(полоса излучения около 2,8 эВ) при $4,2 \mathrm{~K}$. Когда $H=0, A_{\text {т-люми- }}$ несценция затухает по экспоненциальному закону. В магнитном поле, направленном вдоль кристаллографической оси [001] кристалла, затухание описывается суммой двух экспонент. Сильное магнитное поле вызывает очень большие изменения $\tau$. Если при $H=0$ оно равняется $2,3 \cdot 10^{-4}$ с, то с ростом $H$ до 30 Т сокращается до $1 \cdot 10^{-6}$ и $2,5 \cdot 10^{-6}$ с для обоих наблюдаемых экспоненциальных компонентов соответствен-

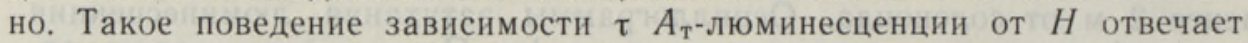
теоретической модели $\left[{ }^{6}\right]$, согласно которой у возбужденного состояния $\ln ^{+}$-центра есть три ориентированных вдоль кристаллографических осей четвертого порядка триплетных минимума энергии, в которых магнитное поле смешивает состояния с разной ориентацией спина и существенно разной вероятностью излучательных переходов в основное состояние. По зависимостям $\tau$ от $H$ вычислены величина расщепления в нулевом поле триплетных состояний на дублет и синглет $2,6 \cdot 10^{-3}$ эВ и вероятность излучательного перехода из дублетного состояния в основное $-1,25 \cdot 10^{6} \mathrm{c}^{-1}$.

Авторы выражают благодарность Я. Шмерлину за помощь при проведении экспериментов.

\section{ЛИТЕ РАТ У РА}

1. Suzuki, K., Miura, N. J. Phys. Soc. Jap., 39, № 1, 148-154 (1975).

2. Гавалешко Н. П., Курик М. В., Скицко Н. Ф. Физ. и техн. полупроводников, 9, вып. 9, 1819-1821 (1975).

3. Харламов Б. М., Улицкий Н. И., Пындык А. М., Подобедов В. Б., Персонов Р. И. Приборы и техн. эксперимента, № 1, 204-207 (1981).

4. Hizhnyakov, V., Kalder, K., Mihkelsoo, V., Niedrais, $H$. Phys. status solidi (b), 101, № $1,431-436$ (1980).

5. Калдер К. А., Ниедрайс Х. Э. В кн.: Тезисы всесоюзного совещания по люминесценции. Л., 1981 , с. 86.

6. Хижняков В. В. Препринт FI-36. Тарту, 1975.

Ннститут физики

Академии наук Эстонской ССР
Поступила в редакцию 17 мая 1982 
K. KALDEER, E. KंUR̆GPOLD,

V. MIHKELSOO, H. NIEDRAIS

\title{
SEADE LUMINESTSENTSI KUSTUMISKINEETIKA MOÖTMISEKS IMPULSSMAGNETVALJAS KUNI $30 \mathrm{~T}$
}

Kirjeldatud seadme põhiosad on heeliumkrüostaat koos sisseehitatud solenoidiga, kondensaatorpatarei mahtuvusega kuni $9 \cdot 10^{-3} \mathrm{~F}$, lämmastiklaser või impulsslamp, fotokordisti ja mäluga ostsillograaf ning sünkronisatsiooniseade.

\author{
K. KALDER, E. KURGPOLD, \\ V. MIHKELSOO, H. NIEDRAIS
}

\section{AN APPARATUS FOR THE MEASUREMENT OF LUMINESCENCE DECAY KINETICS IN PULSED MAGNETIC FIELDS UP TO $30 \mathrm{~T}$}

The paper describes an apparatus for the measurements of decay times of luminescence of the microsecond range in high magnetic fields at $4.2 \mathrm{~K}$. The magnetic field pulses are generated in a stainless steel helium cryostat with a built-in solenoid cooled by liquid nitrogen. The field-producing pulses of the current are generated by the discharges via the solenoid of the capacitor banks. A bank capacity of $9 \cdot 10^{-3} \mathrm{~F}$ and charging voltage of $3.4 \mathrm{kV}$ yields pulses of $30 \mathrm{~T}$ in amplitude and of $5 \cdot 10^{-3} \mathrm{~s}$ duration. To excite luminescence, a pulsed nitrogen laser or a flashlamp is employed. The decay of the luminescence is detected by a photomultiplier and recorded by a storage oscilloscope. The shape of field pulses enables the measurements to be carried out in conditions of an almost constant magnetic field. Fot that purpose, the exeitation of luminescence and the recording of the decay is synchronized with a flat region of a magnetic field pulse around its maximum. 